\title{
Prevalence and determinants of postnatal depression in a tertiary care teaching institute in Kerala, India
}

\author{
Heera Shenoy T. ${ }^{1}$, Remash K. ${ }^{2 *}$, Sheela Shenoy T. ${ }^{3}$
}

\begin{abstract}
${ }^{1}$ Department of Obstetrics and Gynaecology, KMCT Medical College and Hospital, Kozhikode, Kerala, India ${ }^{2}$ Department of Cardiology, Metro-Med International Cardiac Centre, Kozhikode, Kerala, India

${ }^{3}$ Department of Obstetrics and Gynaecology, Government Medical College, Thiruvananthapuram, India
\end{abstract}

Received: 08 July 2019

Accepted: 08 August 2019

\author{
*Correspondence: \\ Dr. Remash K., \\ E-mail: heerarprabhu@gmail.com
}

Copyright: ( ) the author(s), publisher and licensee Medip Academy. This is an open-access article distributed under the terms of the Creative Commons Attribution Non-Commercial License, which permits unrestricted non-commercial use, distribution, and reproduction in any medium, provided the original work is properly cited.

\section{ABSTRACT}

Background: Pregnancy and childbirth produce a variety of physiological, psychological and social consequences. Attitudes toward pregnancy and childbirth vary from culture to culture. Prevalence estimates range from 13 to $19 \%$ in resource-rich settings and 11 to $42 \%$ in resource- limited settings PND has a significant impact on the mother, the family, her partner and mother-infant interaction. This research aims to aid the early diagnosis of postnatal depression and the socio-demographic, obstetric, family dynamics, neonatal characteristics and psychiatric determinants of depression using EPDS among postnatal women in a tertiary hospital in Kerala state, India.

Methods: 119 women between 2 to 6 weeks of postpartum period were subjected to a pre-tested pre-structured standard questionnaire. Diagnosis of depression was made using the Edinburgh postnatal depression scale. Possible depression is values $>13$ or more are invariably associated with depression.

Results: Young age at marriage (p-value 0.022), love marriage (p-value 0.040) and low social support inadequate relationship with the in-laws was significantly associated with PND (p-0.003). Low birth weight was a significant determinant of PND (p-value-0.018). Gender of the new-born, fear and preference towards any particular gender and order of female child in multiparous woman had no association in determining postnatal depression. Childcare stress (p-value-0.011), psychiatry history in family and personal history of depression and mothers with low self-esteem (pvalue-0.001) had odds of developing postnatal depression in the study.

Conclusions: Early screening of the women and counselling of women and their family will reduce the maternal morbidity and adverse child outcomes.

Keywords: Edinburgh postnatal depression scale, Gender, Marriage, Postnatal depression, Postnatal mothers, Relationship, Significant

\section{INTRODUCTION}

Pregnancy and childbirth produce a variety of physiological, psychological and social consequences. Attitudes toward pregnancy and childbirth vary from culture to culture. Affective disorders occur commonly in postnatal period, ranging in severity from mild and transient "baby blues" experienced by $50-80 \%$ of women to postpartum psychosis which affects $1 \%$ of women. Postnatal depression is a nonpsychotic depressive episode of mild to moderate severity, beginning in or extending into the first postnatal year. ${ }^{1}$ PND has a significant impact on the mother, the family, her partner and mother-infant interaction. Young children of mothers with postpartum depression have greater cognitive, behavioural, and interpersonal problems than children of 
non-depressed mothers. ${ }^{2}$ Majority of the mother's exhibit symptoms by 6 week postpartum and if not treated, many women continue to be depressed at the end of the first postpartum year. After one postpartum episode the risk of recurrence, defined as an episode of illness meeting criteria for DSM-IV major depression, is $25 \% .^{3}$

Prevalence estimates range from 13 to $19 \%$ in resourcerich settings and 11 to $42 \%$ in resource- limited settings. ${ }^{4}$ Accurate estimates of PND prevalence are difficult to obtain as cultural norms may affect women's reporting of their symptoms and methods used to determine prevalence rates impact their accuracy. Meta-analysis have found psychosocial and biological risk factors associated with postnatal depression. ${ }^{5}$ Determinants of postnatal depression share themes cross-culturally in resource-rich and resource-limited settings. Prenatal depression, self-esteem, childcare stress, prenatal anxiety, marital relationship, infant temperament, marital status, low social support, socioeconomic status and unplanned/unwanted pregnancy emerged as risk factors in several studies.

Unfortunately, PPD remains under diagnosed and undertreated while most cases of postnatal depression are preventable and largely treatable. In fact, early identification of the same by timely screening can lead to early treatment. Next steps in policy and practice include the need for greater awareness among the public and healthcare professionals of postpartum depression and the local resources available for the optimal treatment of women suffering from it.

Programs related to prevention, early detection, optimal treatments, and amelioration of the effects of postpartum depression on the mother-infant relationship and child growth and development should be encouraged and implemented.

A simple self-reporting Edinburgh postnatal depression scale (EPDS) is useful. ${ }^{1,6}$ This research aims to aid the early diagnosis of postnatal depression and the sociodemographic, obstetric, family dynamics, neonatal characteristics and psychiatric determinants of depression among postnatal women in a tertiary hospital in Kerala state, India.

\section{METHODS}

A cross-sectional study was performed among women delivered in Travancore Medical College and hospital. This study was conducted in Department of Obstetrics and Gynaecology of a tertiary care hospital in state of Kerala India from December 2018 to March 2019.

The studied hospital is attached to a medical college recognized by Medical Council of India with teaching facility for both under and postgraduates in obstetrics and gynaecology.
A total of 119 women, who were in their postpartum state (2-6 weeks) were subjected to a pre-tested, pre-structured, standardised questionnaire, after obtaining an informed written consent. Women with acute severe illness or cognitive impairment or not willing to consent for voluntary participation were excluded.

Primary outcome variable was the prevalence of postnatal depression and secondary outcome variable was various risk factors/determinants for PND.

Data was collected using predesigned and pretested questionnaire. EPDS ("Edinburgh Postnatal depression scale") was used to detect the depressive symptoms and it has been validated for both antenatal and postpartum use and also widely used as screening instrument for detecting symptoms of depression. EPDS scale has ten components in it.

In India, the language versions of the EPDS has been validated as a screening tool to detect prenatal depression in various states and found to have a sensitivity of $100 \%$ and a specificity of $84.9 \%$, at a cut-off score of $12 / 13$. Each item is rated from 0 to 3 , yielding a total score of 0 30. Seven of its items are reverse-scored.

An EPDS score cut off of 13 on Malayalam version of EPDS was used to calculate the prevalence of postnatal depression in the present study. The questionnaire takes approximately 5 minutes to complete. Informed written consent was taken from every participant. To ensure participant privacy data was collected in a separate room.

Ethical approval was obtained from the institutional ethical committee. Each woman was informed about the objectives of study and implications in providing their personal information and only consented women were recruited in the study. They had freedom to opt out from the study without affecting their rights of getting consultation at the hospital. Patient's information was dealt with confidentiality.

Ethical clearance was obtained from Institutional Ethics Committee. Data analysis was done by using SPSS 21 trial version.

\section{Assessment of risk factors.}

A questionnaire was designed and pretested for the assessment of risk factors for PND based on previously reported risk factors. That questionnaire included:

- Social and demographic details including age, educational qualification, family structure (nuclear/joint), occupation, environmental health status (housing, overcrowding), and socio-economic status

- Obstetric history including number and gender of children, present pregnancy (wanted/unwanted, planned/ unplanned, fears and expectations 
regarding gender of child, mode of delivery, complications both during pregnancy and delivery).

- Infant characteristics like birth weight, NICU stay, breast -feeding issues and childcare stress

- History of previous personal and 1st degree family psychiatric disorder, and treatment for the same

- Relationship with and support from the family including relationship with the spouse, parents, and in-laws, Addictions in spouse and domestic abuse were asked.

\section{RESULTS}

In total, 119 new post-natal cases participated in the study. The mean age of the sample was 27.13 years. Out of total 119 women, 35 (29.4\%) were diagnosed with depression using EPDS $>13$ in the study. On comparing the socio-demographic factors among women with depression and women without depression age, education, employment of parents or income had no any association with the postnatal depression (Table 1).

Table 1: Socio-demographic determinants and postnatal depression.

\begin{tabular}{|c|c|c|c|c|}
\hline \multirow{2}{*}{ Mother's age } & \multicolumn{2}{|l|}{ EPDS } & \multirow{2}{*}{ Chi-square } & \multirow{2}{*}{ p-value } \\
\hline & $<=13(\%)$ & $>13(\%)$ & & \\
\hline$<20$ & $3(60.0 \%)$ & $2(40.0 \%)$ & 2.681 & 0.262 \\
\hline $20-30$ & $69(74.2 \%)$ & $24(25.8 \%)$ & & \\
\hline$>30$ & $12(57.1 \%)$ & $9(42.9 \%)$ & & \\
\hline \multicolumn{5}{|l|}{ Father age } \\
\hline$<35$ & $62(74.7 \%)$ & $21(25.3 \%)$ & 2.233 & 0.135 \\
\hline$>35$ & $22(61.1 \%)$ & $14(38.9 \%)$ & & \\
\hline \multicolumn{5}{|l|}{ Domicile } \\
\hline Urban & $49(70.0 \%)$ & $21(30.0 \%)$ & 0.028 & 0.866 \\
\hline Rural & $35(71.4 \%)$ & $14(28.6 \%)$ & & \\
\hline \multicolumn{5}{|c|}{ Education mother } \\
\hline$<10^{\text {th }}$ & $8(80.0 \%)$ & $2(20.0 \%)$ & 0.466 & 0.495 \\
\hline$>10^{\text {th }}$ & $76(69.7 \%)$ & $33(30.3 \%)$ & & \\
\hline \multicolumn{5}{|c|}{ Education father } \\
\hline$<10^{\text {th }}$ & $18(58.1 \%)$ & $13(41.9 \%)$ & 3.167 & 0.075 \\
\hline$>10^{\text {th }}$ & $66(75 \%)$ & $22(25 \%)$ & & \\
\hline \multicolumn{5}{|c|}{ Employment mother } \\
\hline Employed & $26(63.4 \%)$ & $15(36.6 \%)$ & 1.550 & 0.213 \\
\hline Unemployed & $58(74.4 \%)$ & $20(25.6 \%)$ & & \\
\hline \multicolumn{5}{|c|}{ Employment father } \\
\hline Employed & $78(70.9 \%)$ & $32(29.1 \%)$ & 0.072 & 0.788 \\
\hline Unemployed & $6(66.7 \%)$ & $3(33.3 \%)$ & & \\
\hline \multicolumn{5}{|l|}{ Income } \\
\hline Low & $19(63.3 \%)$ & $11(36.7 \%)$ & 1.019 & 0.601 \\
\hline Middle & $41(73.2 \%)$ & $15(26.8 \%)$ & & \\
\hline High & $24(72.7 \%)$ & $9(27.3 \%)$ & & \\
\hline
\end{tabular}

Table 2: Obstetric determinants and postnatal depression.

\begin{tabular}{|c|c|c|c|c|c|}
\hline Characteristic & EPDS & & Odds ratio & Chi-square & p-value \\
\hline & $<=13(\%)$ & $>13(\%)$ & & & \\
\hline \multicolumn{6}{|c|}{ Planned pregnancy } \\
\hline Planned -Yes & $69(68.3 \%)$ & $32(31.7 \%)$ & 0.431 & 1.659 & 0.198 \\
\hline Planned-No & $15(83.3 \%)$ & $3(16.7 \%)$ & & & \\
\hline \multicolumn{6}{|l|}{ Parity } \\
\hline Primigravida & $39(66.1 \%)$ & $20(33.9 \%)$ & 0.650 & 1.135 & 0.287 \\
\hline Multigravida & $45(75 \%)$ & $15(25 \%)$ & & & \\
\hline \multicolumn{6}{|c|}{ GA at delivery in week } \\
\hline$<36.6$ & $18(60.0 \%)$ & $12(40.0 \%)$ & 0.523 & 2.166 & 0.141 \\
\hline$>37$ & $66(74.2 \%)$ & $23(25.8 \%)$ & & & \\
\hline \multicolumn{6}{|c|}{ Mode of delivery } \\
\hline ND & $41(78.8 \%)$ & $11(21.2 \%)$ & 2.080 & 3.034 & 0.082 \\
\hline LSCS & $43(64.2 \%)$ & $24(35.8 \%)$ & & & \\
\hline
\end{tabular}


Table 3: Family dynamics and postnatal depression.

\begin{tabular}{|c|c|c|c|c|c|c|}
\hline \multirow[t]{2}{*}{ Characteristic } & \multicolumn{2}{|l|}{ EPDS } & \multirow[t]{2}{*}{ Odds ratio } & \multirow[t]{2}{*}{ Confidence limits } & \multirow[t]{2}{*}{ Chi-square } & \multirow[t]{2}{*}{ p-value } \\
\hline & $<=13(\%)$ & $>13(\%)$ & & & & \\
\hline \multicolumn{7}{|c|}{ Age at marriage } \\
\hline$<20$ years & $28(75.7 \%)$ & $9(24.3 \%)$ & - & - & 7.665 & $0.022 *$ \\
\hline $20-30$ & $56(70.9 \%)$ & $23(29.1 \%)$ & & & & \\
\hline$>30$ & 00 & $03(100 \%)$ & & & & \\
\hline \multicolumn{7}{|c|}{ Type of marriage } \\
\hline Arranged & $70(76.1 \%)$ & $22(23.9 \%)$ & 2.955 & $1.208-7.224$ & 5.905 & $0.015^{*}$ \\
\hline Love & $14(51.9 \%)$ & $13(48.1 \%)$ & & & & \\
\hline \multicolumn{7}{|l|}{ Relationship } \\
\hline \multicolumn{7}{|l|}{ Spouse } \\
\hline Good & $61(73.5 \%)$ & $22(26.5 \%)$ & 1.567 & $0.679-3.618$ & 1.116 & 0.291 \\
\hline Not good & $23(63.9 \%)$ & $13(36.1 \%)$ & & & & \\
\hline \multicolumn{7}{|l|}{ Parents } \\
\hline$\overline{\text { Good }}$ & $74(73.3 \%)$ & $27(26.7 \%)$ & 2.193 & $0.784-6.134$ & 2.308 & 0.129 \\
\hline Not good & $10(55.6 \%)$ & $8(44.4 \%)$ & & & & \\
\hline \multicolumn{7}{|l|}{ In-law's } \\
\hline Good & $64(79.0 \%)$ & $17(21.0 \%)$ & 3.388 & $1.475-7.782$ & 8.670 & 0.003* \\
\hline Not good & $20(52.6 \%)$ & $18(47.4 \%)$ & & & & \\
\hline \multicolumn{7}{|c|}{ Support in handling/social support } \\
\hline Yes & $49(75.4 \%)$ & $16(24.6 \%)$ & 1.663 & $0.752-3.678$ & 1.587 & 0.208 \\
\hline No & $35(64.8 \%)$ & $19(35.2 \%)$ & & & & \\
\hline
\end{tabular}

Table 4: Neonatal characteristics and postnatal depression.

\begin{tabular}{|c|c|c|c|c|c|c|}
\hline Characteristic & EPDS & & Odds ratio & Confidence limits & Chi-square & p-value \\
\hline Baby gender & $<=13(\%)$ & $>13(\%)$ & & & & \\
\hline Female & $46(67.6 \%)$ & $22(32.4 \%)$ & 0.715 & $0.318-1.607$ & 0.661 & 0.416 \\
\hline Male & $38(74.5 \%)$ & $13(25.5 \%)$ & & & & \\
\hline \multicolumn{7}{|l|}{ Birth weight } \\
\hline$<2499 \mathrm{~g}$ & $62(77.5 \%)$ & $18(22.5 \%)$ & 2.662 & $1.170-6.056$ & 5.617 & $0.018 *$ \\
\hline$>2500 \mathrm{~g}$ & $22(56.4 \%)$ & $17(43.6 \%)$ & & & & \\
\hline \multicolumn{7}{|c|}{ Order of female child in multipara } \\
\hline & $\mathrm{N}=41$ & $\mathrm{~N}=15$ & & & & \\
\hline First & $22(78.6 \%)$ & $6(21.4 \%)$ & 1.737 & $0.522-5.776$ & 0.82 & 0.365 \\
\hline$>$ Second & $19(67.9 \%)$ & $9(32.1 \%)$ & & & & \\
\hline \multicolumn{7}{|c|}{ Child care stress } \\
\hline Yes & $10(47.6 \%)$ & $11(52.4 \%)$ & 0.295 & $0.112-0.780$ & 6.48 & $0.011 *$ \\
\hline No & $74(75.5 \%)$ & $24(24.5 \%)$ & & & & \\
\hline \multicolumn{7}{|c|}{ Breast feeding problems } \\
\hline Yes & $26(65.0 \%)$ & $14(35.0 \%)$ & 0.672 & $0.296-1.526$ & 0.906 & 0.341 \\
\hline No & $58(73.4 \%)$ & $21(26.6 \%)$ & & & & \\
\hline \multicolumn{7}{|l|}{ Gender fear } \\
\hline Yes & $26(63.4 \%)$ & $15(36.6 \%)$ & 0.598 & $0.265-1.349$ & 1.550 & 0.213 \\
\hline No & $58(74.4 \%)$ & $20(25.6 \%)$ & & & & \\
\hline \multicolumn{7}{|c|}{ Gender preference } \\
\hline Yes & $57(70.4 \%)$ & $24(29.6 \%)$ & 0.968 & $0.414-2.259$ & 0.006 & 0.939 \\
\hline No & $27(77.14 \%)$ & $11(22.86 \%)$ & & & & \\
\hline
\end{tabular}

Comparison of the obstetric factors among women with PPD and without it showed that depression was not significantly associated with parity, gestational age at birth, mode of delivery whether pregnancy was planned or not (Table 2). 
Young age at marriage (p-value 0.022), love marriage ( $\mathrm{p}$ value 0.040) and low social support inadequate relationship with the in-laws was also significantly associated with depression among post -natal women ( $\mathrm{p}$ 0.003) (Table 3).

Low birthweight was a significant determinant of PND (p-value-0.018). Gender of the new-born, fear and preference towards any particular gender and order of female child in multiparous woman had no association in determining postnatal depression. Child care stress (pvalue-0.011) increased the odds of PND (Table 4).

Similarly, PND risk increased many fold (OR 15.868 and 14.178) (p-value 0.0001) among women who had psychiatry history in family and personal history of depression. Women with low self-esteem (p-value0.001) had 14.352 odds of developing postnatal depression in the study (Table 5).

Table 5: Psychiatric determinants of postnatal depression.

\begin{tabular}{|c|c|c|c|c|c|c|}
\hline \multirow[t]{2}{*}{$\begin{array}{l}\text { Personal history of } \\
\text { depression }\end{array}$} & \multicolumn{2}{|l|}{ EPDS } & \multirow[t]{2}{*}{ Odds ratio } & \multirow[t]{2}{*}{ Confidence limits } & \multirow[t]{2}{*}{ Chi-square } & \multirow[t]{2}{*}{ p-value } \\
\hline & $<=13(\%)$ & $>13(\%)$ & & & & \\
\hline Yes & $6(33.3 \%)$ & $12(66.6 \%)$ & 0.147 & $0.050-0.436$ & 14.178 & $0.001 *$ \\
\hline No & $78(77.2 \%)$ & $23(22.8 \%)$ & & & & \\
\hline \multicolumn{7}{|c|}{ Psychiatric illness in family } \\
\hline Yes & $3(23.1 \%)$ & $10(76.9 \%)$ & 0.093 & $0.024-0.363$ & 15.868 & $0.001 *$ \\
\hline No & $81(76.4 \%)$ & $25(23.6 \%)$ & & & & \\
\hline \multicolumn{7}{|l|}{ Self esteem } \\
\hline Low & $13(43.3 \%)$ & $17(56.7 \%)$ & 0.194 & $0.080-0.471$ & 14.352 & $0.001 *$ \\
\hline Good & $71(79.8 \%)$ & $18(20.2 \%)$ & & & & \\
\hline
\end{tabular}

Table 6: Mean characteristics of the study group.

\begin{tabular}{|lllll|}
\hline Variables & Mean $(\mathbf{n = 1 1 9})$ & EPDS & Significance* \\
\hline Maternal age & & $<=13(\mathbf{n = 8 4})$ & $\mathbf{> 1 3}(\mathbf{n = 3 5})$ & 0.246 \\
\hline Paternal age & 27.13 & 26.85 & 27.83 & 0.495 \\
\hline Age at marriage & 33.00 & 32.81 & 33.46 & 0.074 \\
\hline Height & 22.73 & 22.35 & 23.66 & 0.325 \\
\hline Weight & 157.02 & 157.35 & 156.23 & 0.168 \\
\hline Baby weight & 67.03 & 68.13 & 64.37 & 0.095 \\
\hline GA at delivery & 2658.40 & 2769.23 & 2519.03 & 0.065 \\
\hline NICU days & 36.976 & 37.344 & 36.091 & 0.624 \\
\hline
\end{tabular}

*Independent sample t test

Both maternal and paternal age were slightly higher while maternal height and weight were slightly lower in EPDS $>13$ than controls and hence not statistically significant. Low birth weight being a significant predictor of PND as evidenced by babies of depressed mothers weighing 250 grams lower than the controls. Babies of mothers with EPDS >13 spent 0.67 more days in NICU .Mean GA at delivery in week of EPDS >13 was 36.091 (Table 6).

\section{DISCUSSION}

Reported prevalence of PND in this study was $29.4 \%$. The prevalence of PND ranges from $7.6 \%$ to $39 \%$ in various areas of the world and differs according to the population tested and screening tools used..$^{7-10}$ Study done in Goa, Mangalore and Delhi showed the prevalence $22 \%$ $31.44 \%$ and $24 \%$ respectively. ${ }^{11-13}$

Very wide range of PND prevalence has been reported in studies from China (11\%), United Arab Emirates $(15.8 \%) .{ }^{14,15}$ Predicting PND in a similar prospective cohort study in Zimbabwe found $16 \%$ prevalence. ${ }^{16}$ Southern Brazil had a PND prevalence of 20.7\%. ${ }^{17}$ Cooper et al in his study on prevalence of postnatal depression in South Africa had $34.7 \%$ and it was highest in Pakistan (40\%). ${ }^{19}$ The present study may have overestimated the actual PND prevalence as EPDS is a screening tool but not confirmatory. Using the EPDS women who exceed a threshold score of 10 (within family practices) and 12 (within research studies) have a greater likelihood of being depressed, we took a cut-off 
the EPDS $>13 .{ }^{1,6}$ Genetic and biological studies of mood disorders indicate that they have complex etiology, and even if an individual has a genetic vulnerability or predisposition to developing depression, there have to be experiential and environmental factors which interact to cause the illness.

Therefore, it is likely that a number of these factors play a role in the development of postpartum depression such as study tools and technique differences, socio-cultural norms and poverty levels. ${ }^{20}$ All women are susceptible to developing depression following childbirth.

In the present study there was no significant association between the age, socio economic status and literacy status of the women with the prevalence of postnatal depression in contrast to a study done in Nepal and Mangalore. ${ }^{21-22}$ Parity, planning of pregnancy, mode of delivery and type of delivery had no association in the study and similar to studies globally. ${ }^{4,23}$ Research which has examined the rates of postpartum depression in mothers aged 14-18 years showed a much higher rate of PND, approximately $26 \% .^{24}$ A study on Chinese women had also shown significant association between the younger age and PPD. ${ }^{25}$ Low income population studies within India, China and Canada found that financial strain was an important risk factor in postpartum depression within these populations which was not noted in the study population. ${ }^{11,14,26}$

Gender of the baby, fear of gender /preference towards any particular gender had no role in determining postnatal depression similar to studies conducted within Western societies where there was no association between the sex of the child and postpartum depression while it is in striking contrast with several Indian studies where mothers who gave birth to a female child had an increased odds of developing PND. ${ }^{11,27}$ Birth of baby girl is considered as a family and social stressor in Indian societies in contrast to the matriarchy favouring attitude in our state of Kerala. Planning of pregnancy, operative and difficult deliveries had positive correlation with PND in various studies in contrast to the study. ${ }^{2,15}$

Personal and family history of depression and inadequate relationship with her in - laws were significantly associated with PND in the present study and in a similar study in Delhi, Bangalore Johnstone et al..$^{28-30}$

In the present study, poor support from the baby's father was not significantly associated with being diagnosed with postpartum depression. Women with low selfesteem had 14.352 odds of developing postnatal depression in the study. Receiving social support through friends and relatives during stressful times is thought to be a protective factor against developing depression. ${ }^{31}$ Perceived social isolation (or lack of social support) was a strong risk factor for depressive symptoms postpartum..$^{9,32,33}$
Logsdon et al, studied social support among AfricanAmerican low income pregnant women and found a significant relationship between perceived support and depressive symptomatology following delivery, there was no relationship between received support and postpartum depression which was emphasised that social support received was not a predictor for PND. ${ }^{34}$ Beck studied two variables related to the infant, child temperament and childcare stress and he found that childcare stress and having an infant with a difficult temperament were at increased odds of developing postpartum depressive symptomatology similar to the observation in the research. ${ }^{5}$

Similar to the observation there was no overall statistically non-significant relationship between obstetric history, labour and delivery, complications of pregnancy and breast feeding in postpartum depression as in similar studies..$^{30,32,35,36}$ No significant association between elective or emergency caesarean section and subsequent postpartum depression were noted in similar studies as in the present study. ${ }^{32-35}$ Significant relationship between unplanned pregnancy and depression at 6 weeks postpartum were noted in certain studies ${ }^{37}$ but we found no correlation.

\section{CONCLUSION}

The authors propose that mothers-to-be in these risk groups could benefit from screening for the presence of PND. Since the risk is linked with experience of psychosocial stressors, it seems that they might benefit from increased psychosocial support social counselling, couple counselling, family and friend support to prevent affective pathology.

\section{ACKNOWLEDGMENTS}

Authors would like to thank Department of Obstetrics and Gynaecology and Department of Psychiatry, Travancore Medical College for their support during study.

\section{Funding: No funding sources}

Conflict of interest: None declared

Ethical approval: The study was approved by the Institutional Ethics Committee

\section{REFERENCES}

1. Cox JL, Holden JM, Sagovsky R. Detection of postnatal depression. Development of the 10-item Edinburgh Postnatal Depression Scale. $\mathrm{Br}$ J Psychiatry. 1987;150:782-6.

2. Hara MW, Cabe JE. Postpartum depression: current status and future directions. Annu Rev Clin Psychol. 2013;9:18-25.

3. Wisner KL, Parry BL, Piontek CM. Clinical practice. Postpartum depression. N Engl J Med. 2002;347:194-9. 
4. Hegde S, Latha KS, Bhat SM, Sharma PS, Kamath A, Shetty AK. Postpartum depression: prevalence and associated factors among women. Indian $\mathrm{J}$ Women Health Issues Care. 2012;1:13-7.

5. Beck CT. Predictors of postpartum depression. An Update. Nursing Research. 2001;50:275-85.

6. Rubertsson C, Börjesson K, Berglund A, Josefsson A, Sydsjö G. The Swedish validation of Edinburgh Postnatal Depression Scale (EPDS) during pregnancy. Nord J Psychiatry. 2011;65:414-8.

7. Sword W, Landy KC, Thabane L, Watt S, Krueger P, Farine D, Foster G. Is mode of delivery associated with postpartum depression at 6 weeks: a prospective cohort study? BJOG: Int J Obstet Gynaecol. 2011;118:966-77.

8. Mccoy SJB, Beal JM, Saunders B, Hill EN, Payton ME, Watson GH. Risk factors for postpartum depression: a retrospective investigation. J Reprod Med. 2008;53(3):166-70.

9. Chaaya M, Campbell OMR, Kak FE, Shaar D, Harb $\mathrm{H}$, Kaddour A. Postpartum depression: prevalence and determinants in Lebanon. Arch Women's Mental Health. 2002;5(2):65-72.

10. Gonidakis F, Rabavilas AD, Varsou E, Kreatsas G, and Christodoulou GN. A 6-month study of postpartum depression and related factors in Athens Greece. Comprehens Psychiatr. 2008;49(3):275-82.

11. Patel V, Rodrigues M, DeSouza M. Gender, poverty, and postnatal depression: a study of mothers in Goa, India. Ame J Psychiatry. 2002;159:43-7.

12. Shivalli S, Gururaj N. Postnatal Depression among rural women in South India: Do socio-demographic, obstetric and pregnancy outcome have a role to play? PLoS ONE. 2015;10(4):1-11.

13. Dhande N, Khapre M, Nayak S, Mundey A. Assessment of postnatal depression among mothers following delivery in rural area of Wardha district: A cross sectional study. Innovative Journal of Medical and Health Science. 2014;4:53-5.

14. Lee D, Yip A, Chiu H, Leung T, Chung T. A psychiatric epidemiological study of postpartum Chinese women. Am J Psychiatry. 2001;158:22-26.

15. Ghubash R, Saleh MT. Postpartum psychiatric illness in Arab culture: prevalence and psychosocial correlates. Br J Psychiatry. 1997;171:65-8.

16. Nhiwatiwa S, Patel V, Acuda W. Predicting postnatal mental disorder with a screening questionnaire: a prospective cohort study from Zimbabwe. J Epidemiol Community Health. 1998;52:262-66.

17. Tannous L, Gigante LP, Fuchs SC, Busnello ED. Postnatal depression in Southern Brazil: prevalence and its demographic and socioeconomic determinants. BMC Psychiatry. 2008;8:1.

18. Cooper PJ, Tomlinson M, Swartz L, Woolgar M, Murray L. Postpartum depression and the motherinfant relationship in a South African periurban settlement. Br J Psychiatry. 1999;175:554-8.

19. Rahman A, Lovel H, Bunn J, Iqbal Z, Harrington R. Mother's mental health and infant growth: a case- control study from Rawalpindi, Pakistan. Child Care Health Dev. 2004;30:21-7.

20. Dubovsky SL, Buzan R. Mood Disorders. In RE Hales, SC Yudofsky, JA Talbott (Eds.), Textbook of Psychiatry. 3rd ed. Washington, DC: American Psychiatric Press; 1999:479-565

21. Clarke K, Saville N, Shrestha B, Costello A, King M, Manandhar D. Predictors of psychological distress among postnatal mothers in rural Nepal: a cross-sectional community-based study. J Affective Disorder. 2014;156:76-86.

22. Kruthika K, Udayar SE, Mallapur MD. An epidemiological study of postnatal depression among women availing maternal health services in rural areas of Belagavi, Karnataka, India. Int J Community Med Public Health. 2017;4:759-63.

23. Milgrom J, Gemmill AW, Bilszta JL, Hayes B, Barnett B, Brooks J. Antenatal risk factors for postnatal depression: a large prospectivestudy. J Affect Disord. 2008;108:147-57.

24. Troutman BR, Cutrona CE. Nonpsychotic postpartum depression among adolescent mothers. Journal of Abnormal Psychology. 1990;99:69-78.

25. Siu BW, Leung SS, Ip P, Hung SF, O’Hara MW. Antenatal risk factors for postnatal depression: a prospective study of Chinese women at maternal and child health centres. BMC Psychiatry. 2012;12:22.

26. Seguin L, Potvin L, Denis M, Loiselle J. Depressive symptoms in the late postpartum among low socioeconomic status women. Birth. 1999;26:157163.

27. Chandran M, Tharyan P, Muliyil J, Abraham .Postpartum depression in a cohort of women from a rural area of Tamil Nadu, India. Incidence and risk factors. Br J Psychiatry. 2002;181:499-50.

28. Gupta S, Kishore J, Mala YM, Ramji S, Aggarwal R. Postpartum depression in north indian women: prevalence and risk factors. J Obst Gynaecol India. 2013;63(4):223-9.

29. Suguna A, Naveen R, Surekha A. Postnatal depression among women attending a rural maternity hospital in South India. Ntl J Community Med. 2015;6(3):297-301.

30. Johnstone SJ, Boyce PM, Hickey AR, Yatees AD, Harris MG. Obstetric risk factors for postnatal depression in urban and rural community samples. Australian New Zealand J Psych. 2001;35:69-74.

31. Brugha TS, Sharp HM, Cooper SA, Weisender C, Britto D, Shinkwin R. The Leicester 500 Project. Social support and the development of postnatal depressive symptoms, a prospective cohort survey. Psychological Medicine. 1998;28:63-79.

32. Forman DN, Videbech P, Hedegaard M, Salvig JD, Secher NJ. Postpartum depression: identification of women at risk. British $\mathrm{J}$ Obst Gynaecol. 2000;107:1210-1217.

33. Nagandla K, Nalliah S, Yin LK, Majeed ZA, Ismail M, Zubaidah S. Prevalence and associated risk factors of depression, anxiety and stress in 
pregnancy. Int J Reprod Contracept Obstet Gynecol. 2016;5:2380-8.

34. Logsdon MC, Birkimer JC, Usui WM. The link of social support and postpartum depressive symptoms in African-American women with low incomes. Am J Matern Child Nurs. 2006;25:262-6.

35. Warner R, Appleby L, Whitton A, Faragher B. Demographic and obstetric risk factors for postnatal psychiatric morbidity. British J Psych. 1996;168:607-11.

36. Josefsson A, Angelsioo L, Berg G, Ekstrom CM, Gunnervik C, Nordin C. Obstetric, somatic, and demographic risk factors for postpartum depressive symptoms. Obst Gynecol. 2002;99:223-8.

37. Boyce PM, Todd AL. Increased risk of postnatal depression after emergency caesarean section. Med J Aust. 1992;157:172-4.

Cite this article as: Shenoy HT, Remash K, Shenoy ST. Prevalence and determinants of postnatal depression in a tertiary care teaching institute in Kerala, India. Int J Reprod Contracept Obstet Gynecol 2019;8:3757-64. 